\title{
Strategies to Improve Cancer Immune Checkpoint Inhibitors Efficacy, Other Than Abscopal Effect: A Systematic Review
}

\author{
Vito Longo ${ }^{1,+}$, Oronzo Brunetti ${ }^{2,+}\left(\mathbb{D}\right.$, Amalia Azzariti $^{3}$, Domenico Galetta ${ }^{1} \mathbb{D}$, Patrizia Nardulli ${ }^{4}$, \\ Francesco Leonetti ${ }^{5, \ddagger}$ and Nicola Silvestris ${ }^{6, *, \ddagger}$ \\ 1 Medical Thoracic Oncology Unit, IRCCS Istituto Tumori “Giovanni Paolo II”, Viale Orazio Flacco, 65, \\ 70124 Bari, Italy; vito.longo79@tiscali.it (V.L.); galetta@oncologico.bari.it (D.G.) \\ 2 Medical Oncology Unit, Hospital of Barletta, Viale Ippocrate, 15, 70051 Barletta, Italy; \\ dr.oronzo.brunetti@tiscali.it \\ 3 Experimental Pharmacology Laboratory, IRCCS Istituto Tumori “Giovanni Paolo II”, Viale Orazio Flacco, 65, \\ 70124 Bari, Italy; a.azzariti@oncologico.bari.it \\ 4 Pharmacy Unit, IRCCS Istituto Tumori “Giovanni Paolo II", Viale Orazio Flacco, 65, 70124 Bari, Italy; \\ p.nardulli@oncologico.bari.it \\ 5 Dipartimento di Farmacia-Scienze del Farmaco, University of Bari, Piazza Umberto I, 1, 70121 Bari, Italy; \\ francesco.leonetti@uniba.it \\ 6 Scientific Guidance, IRCCS Istituto Tumori “Giovanni Paolo II”, Viale Orazio Flacco, 65, 70124 Bari, Italy \\ * Correspondence: n.silvestris@oncologico.bari.it; Tel.: +39-0805-555-419 \\ + These authors contributed equally to this work as the first authors. \\ $\ddagger$ These authors contributed equally to this work as the last authors.
}

Received: 26 March 2019; Accepted: 12 April 2019; Published: 15 April 2019

check for updates

\begin{abstract}
Despite that the impact of immune checkpoint inhibitors on malignancies treatment is unprecedented, a lack of response to these molecules is observed in several cases. Differently from melanoma and non-small cell lung cancer, where the use of immune checkpoint inhibitors results in a high efficacy, the response rate in other tumors, such as gastrointestinal cancers, breast cancer, sarcomas, and part of genitourinary cancers remains low. The first strategy evaluated to improve the response rate to immune checkpoint inhibitors is the use of predictive factors for the response such as PD-L1 expression, tumor mutational burden, and clinical features. In addition to the identification of the patients with a higher expression of immune checkpoint molecules, another approach currently under intensive investigation is the use of therapeutics in a combinatory manner with immune checkpoint inhibitors in order to obtain an enhancement of efficacy through the modification of the tumor immune microenvironment. In addition to the abscopal effect induced by radiotherapy, a lot of studies are evaluating several drugs able to improve the response rate to immune checkpoint inhibitors, including microbiota modifiers, drugs targeting co-inhibitory receptors, anti-angiogenic therapeutics, small molecules, and oncolytic viruses. In view of the rapid and extensive development of this research field, we conducted a systematic review of the literature identifying which of these drugs are closer to achieving validation in the clinical practice.
\end{abstract}

Keywords: immune checkpoint inhibitors; chemotherapy; tyrosine kinase inhibitors; angiogenesis

\section{Introduction}

Today, immune checkpoint inhibitors (ICIs) represent a gold standard treatment in the first-line setting of several tumors, including non-small cell lung cancer (NSCLC) [1-3], BRAF wild-type (WT) melanoma [4] and metastatic renal cell carcinoma (mRCC) [5]. These molecules are antibodies 
which block checkpoint molecules such as s cytotoxic T-lymphocyte-associated antigen-4 (CTLA-4) and programmed-death1/programmed death-ligand 1 (PD-1/PD-L1). These interferences reduce the immune suppressive mechanisms increasing the immune responses against cancer and can result in tumor regression in many patients. Over time, the CTLA-4 and PD-1 blockade improved overall survival and the survival rate of many tumors, and have been tested in many others with excellent oncological outcomes. Although these molecules appear to be very promising, there are many limitations such as notable side effects (i.e., endocrine failure, gastrointestinal and pulmonary toxicities). Anyway, one of the biggest disadvantages is that ICIs present a lower activity in several cancers, such as those with low mutational burden. Moreover, even for some pathologies where ICIs have a greater activity, there are some patients that do not show any benefit. However, in some cases there is a lack of response to these molecules [6-8].

Mainly, two strategies are considered to improve the response rate to ICIs. The first is represented by the selection of patients according to specific predictive factors (i.e., PD-L1 expression, tumor mutational burden (TMB), and clinical features). The second strategy has the aim to enhance the efficacy of ICIs, with the abscopal effect induced by radiotherapy representing the most frequently evaluated approach in both pre-clinical and clinical setting $[9,10]$. However, in the last few years, several studies were focused on the potential role of molecules as it is able to improve the response rate to ICIs by modifying the immune microenvironment of the tumor, increasing the number of activated $\mathrm{T}$ cells exerting effector functions, and decreasing the number of immunosuppressive cells thus transforming a cold tumor into a hot one. These drugs include microbiota modifiers, drugs targeting co-inhibitory receptors, anti-angiogenic therapeutics, small molecules, and oncolytic viruses. A systematic review of the literature was conducted, considering only the drug classes which are under evaluation in the clinical setting and as far as they could be considered in the clinical practice in the near future. The research has been conducted considering papers published on PubMed and data presented to the ASCO and ESMO annual meeting. The aim of this systematic review is to evaluate all the drugs, molecules, and viruses which could improve the activity of ICIs. In particular, we evaluate the immunological mechanisms, which lead to enhance ICIs immune anti-cancer.

\section{Materials and Methods}

\subsection{Research Strategy}

The research strategy was designed to identify published peer-reviewed studies that research the combination of ICIs and other therapies to improve the anti-tumor immune response. The review covered all countries; no time limit has been set to ensure the identification of a wide range of articles. A web-based search of MEDLINE/PubMed library data published from 2010 to December 2018 was performed. Additional research was performed on ClinicalTrials.gov (Figure 1). Search terms were generated to encapsulate the effect of ICIs on cancer and the increase in the antitumor effect (Table 1).

\subsection{Inclusion/Exclusion Criteria}

To be eligible, papers had to be written in English, published in a peer-reviewed journal, be original primary research including experimental, observational, and qualitative studies.

The relevant outcomes explored were further investigated as there was a demonstrated role for greater efficacy of the ICI anti-cancer effect when these were administrated in combination with other therapies. The authors excluded the use of ICIs in combination with radiotherapies or other local or regional treatments.

\subsection{Study Selection}

All studies identified through the search process were exported to EndNoteversion X7(ClarivateAnalytic 22 Thomson Place, 36T3 Boston, MA, USA). Duplicates were removed. Two authors (O.B. and V.L.) have independently doubled the titles, abstracts and keywords with the 
eligibility criteria. The results were compared and full-text records of potentially relevant publications were obtained and screened using the inclusion criteria for the final selection of studies for systematic review (Figure 1).

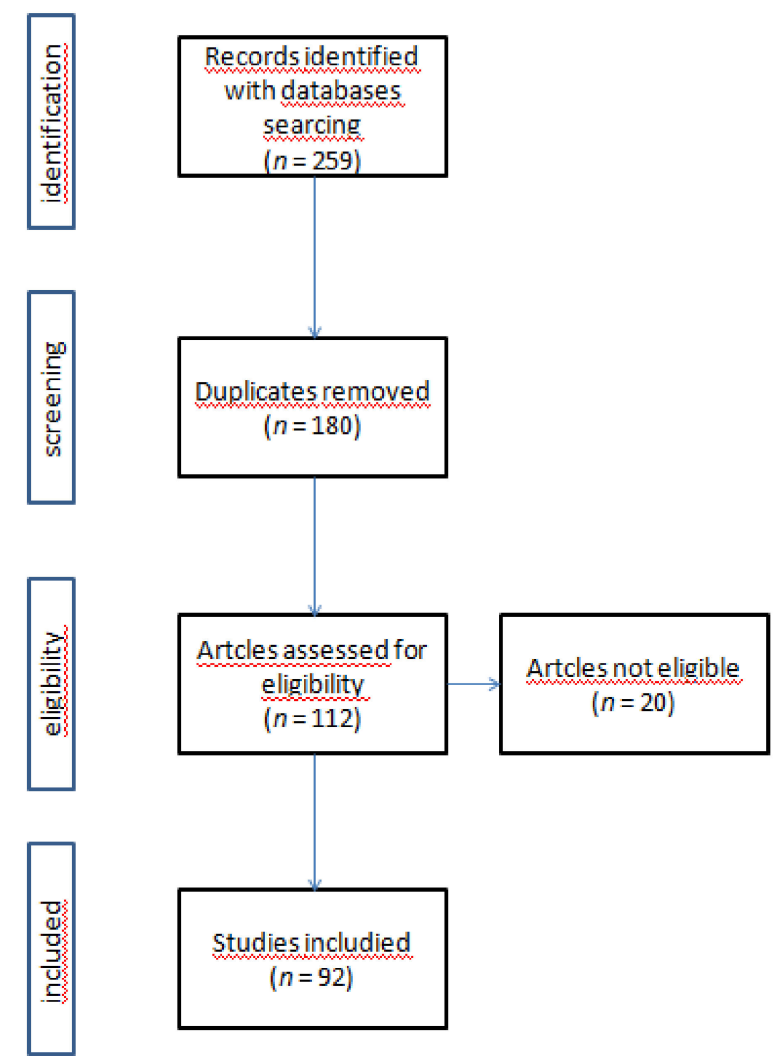

Figure 1. Research strategy with PRISMA flow diagram.

Table 1. Search terms.

\begin{tabular}{|c|c|}
\hline Immune Therapy & Enhancer \\
\hline $\begin{array}{l}\text { 'immune checkpoint inhibitors', } \\
\text { 'anti-PD-(L)1', 'anti-CTLA-4'. }\end{array}$ & $\begin{array}{c}\text { "microbiote" OR "microbiota" OR "gut microbe" } \\
\text { OR "bacteria" }\end{array}$ \\
\hline $\begin{array}{l}\text { 'immune checkpoint inhibitors', } \\
\text { 'anti-PD-(L)1', 'anti-CTLA-4'. }\end{array}$ & $\begin{array}{l}\text { "chemotherapy" OR" chemotherapeutics" OR } \\
\text { "metronomic chemotherapy" }\end{array}$ \\
\hline $\begin{array}{l}\text { 'immune checkpoint inhibitors', } \\
\text { 'anti-PD-(L)1', 'anti-CTLA-4'. }\end{array}$ & $\begin{array}{c}\text { "anti-angiogenetic therapies" OR "bevacizumab" } \\
\text { OR "nintedanib" OR "Aflibercept" OR "pazopanib" } \\
\text { OR "sunitinib" }\end{array}$ \\
\hline $\begin{array}{l}\text { 'immune checkpoint inhibitors', } \\
\text { 'anti-PD-(L)1', 'anti-CTLA-4'. }\end{array}$ & $\begin{array}{c}\text { "co-inhibitor receptors" OR “TIGIT” OR “LAG3” } \\
\text { OR “TIM-3” }\end{array}$ \\
\hline $\begin{array}{l}\text { 'immune checkpoint inhibitors', } \\
\text { 'anti-PD-(L)1', 'anti-CTLA-4'. }\end{array}$ & $\begin{array}{l}\text { “Oncolytic virus" OR “adenovirus" OR "vaccinia } \\
\text { viruses" OR "Coxsackieviruses" OR "Reoviruses" }\end{array}$ \\
\hline $\begin{array}{l}\text { 'immune checkpoint inhibitors', } \\
\text { 'anti-PD-(L)1', 'anti-CTLA-4'. }\end{array}$ & $\begin{array}{l}\text { "small molecules" OR "tyrosine kinase inhibitor" } \\
\text { OR "mTOR inhibitor" OR "cyclin inhibitor" }\end{array}$ \\
\hline
\end{tabular}

A group of experts provided additional biological and clinical information, greatly helping to clarify some issues in the absence of clear information from the literature.

The final draft was then submitted to expert evaluation and modified according to their suggestions and comments. 


\section{Microbiota and ICIs}

Microbiota plays a crucial role in the development of host immunity [11]. In several pathologies (i.e., inflammatory bowel disease, diabetes, obesity, atherosclerosis, asthma, and dysmetabolic syndromes) gut commensals resulted in being disrupted in comparison with those of unaffected individuals [12,13].

Regarding the relationship between microbiota and ICIs, the administration of a combination of broad-spectrum antibiotics (i.e., ampicillin plus colistin plus streptomycin) as well as imipenem alone compromised antitumor effects of CTLA-4 monoclonal antibody (mAb) as a consequence of microbiota impairment. Moreover, prescription of antibiotics in patients treated with anti-PD-1/PD-L1 $\mathrm{mAb}$ between two months before and two months after the start of immunotherapy resulted in a worse prognosis [14], implying a critical role of microbiota in the modulation of response to ICIs.

In 2015 Vetizou et al. [15] found that antitumor effects of anti-CTLA-4 mAb depended on distinct samples of Bacteroides (B). In particular, the authors demonstrated that the specific $\mathrm{T}$ cell response for B. thetaiotaomicron and B. fragilis was associated to the efficacy of anti-CTLA-4 administration in mice inoculated with MCA205 sarcomas, Ret melanoma, and MC38 colon cancer cells. Gut bacterial disruption led to a reduction of anticancer response. This deficiency was overcome by administration of B. fragilis, through immunization with B. fragilis polysaccharides, or by adoptive transfer of B. fragilis-specific $T$ cells. Feces transplantation from patients with metastatic melanoma responsive to anti-CTLA-4 in mice inoculated with cancer cells favored the outcome of these mouse tumor models [15]. In fact, the authors re-colonized both germ-free mice and antibiotics treated with bacterial species, finding that B. fragilis, B. thetaiotaomicron, B. cepacia, or the combination of B. fragilis and B. cepacia could restore the anti-CTLA-4 mAb effects. Oral combination of B. fragilis and Burkholderia cepacia could restore the efficacy of CTLA4 blockade in animals treated with antibiotics, without incurring colitis $[15,16]$. These data were confirmed in a prospective study considering patients with metastatic melanoma treated with ipilimumab. The intestinal microbiome enriched with B. phylum was correlated with a low incidence of checkpoint-block-induced colitis [17].

In another preclinical study, Sivan et al. [18] compared the growth kinetics of B16.SIY melanoma cells subcutaneously inoculated in two genetically similar C57BL/6 mice from Taconic Farms (TAC) and the Jackson Laboratory (JAX) which contained different intestinal bacterial communities [18]. TAC mice generated more aggressive tumors than JAX mice. On the contrary, tumor-infiltrating specific CD8+ T cells were more evident in JAX mice than in TAC mice. The Bifidobacterium genus was identified as a driver of tumor response in JAX mice. When both mice were co-housed, all animals showed a JAX phenotype, suggesting that an enhanced immune response was potentiated by microbes. Moreover, administration of a mixed Bifidobacterium subspecies altered tumor growth in TAC mice [18].

Patients with baseline bacterial species with a prevalence of the Faecalibacterium genus and other Firmicutes had a significantly longer progression-free survival (PFS) and overall survival (OS) with a more frequent occurrence of colitis than patients with microbiota characterized by the prevalence of $B$. Moreover, some of these patients reached an OS longer than 18 months [19].

Another study evaluated the therapeutic efficacy of human intestinal microbiota and its metabolites with different ICIs (i.e., ipilimumab, nivolumab, ipilimumab plus nivolumab, or pembrolizumab). The intestinal microbiota of responder patients was enriched by B. caccae with high levels of anacardic acid. In particular, the bacterial microbiome of patients responsive to the combination of nivolumab plus ipilimumab and pembrolizumab was enriched by Faecalibacteriumprausnitzii, B. thetaiotamicron, Holdemaniafiliformis, and Doreaformicogenerans [20].

In 2018, two parallel studies evaluated the role of the microbiome of melanoma patients treated with anti-PD-1. The first analyzed the oral microbiome of 112 patients without significant differences between responders and non-responders, although the fecal microbiota samples of 30 responders to ICI showed a significant presence of Ruminococcaceae bacteria $(p<0.01)$. In the second study 38 and four patients were treated with anti PD1 and anti CTLA4, respectively. A higher presence of Bifidobacterium longum, Collinsellaaerofaciens, Enterococcus faecium, Bifidobacterium adolescentis, 
Kleibsiella pneumonia, Veillonellaparvula, Parabacteriodesmerdae, and lactobacillus sp. was observed in the intestines of responders compared to those found in non-responders. Moreover, transplantation of fecal material from responding patients into germ-free mice improved tumor control more effectively than anti-PD-L1 therapy in both studies [21,22].

The microbiome was evaluated in 249 patients with NSCLC, mRCC, and urothelial carcinoma (UC) treated with anti-PD-1 [14]. Genomic analysis of patients' stool samples revealed a significant correlation between response to treatment and high presence of Akkermansia muciniphila. The antitumor effects of the anti PD-1 blockade were improved when the fecal microbiota from patients with a responding tumor were transplanted into germ-free or antibiotic-treated mice. In contrast, fecal transplantation from patients who did not respond to germ-free mice did not achieve any results. Oral supplementation with Akkermansia muciniphila in these latter mice has restored the efficacy of PD-1.

Sivan et al. [18] demonstrated greater expression of the major class I and II histocompatibility complex in dendritic cells (DCs) of JAX mice or Bifidobacterium colonized TAC mice. All the above studies showed an influence of the microbiota on DC maturation and activation (Figure 2). An increase in the rate ofCD8+/Treg was observed in mice transplanted with fecal samples from ICI-sensitive patients. The analysis of tumor infiltrates also revealed the increase of innate effector cells and the reduction of myeloid-derived suppressor cells (MDSCs) [21,22]. Moreover, the administration of Akkermansia muciniphila in germ-free mice treated with anti-PD-1was associated with increased frequency of T helper1 Tregs/tumoral helper1 cells. Finally, the oral administration of A. muciniphila and E. hiraestimulates leads DCs to increase the production of IL-12, a cytokine involved in the inhibition of PD-1 under physiological conditions [14].

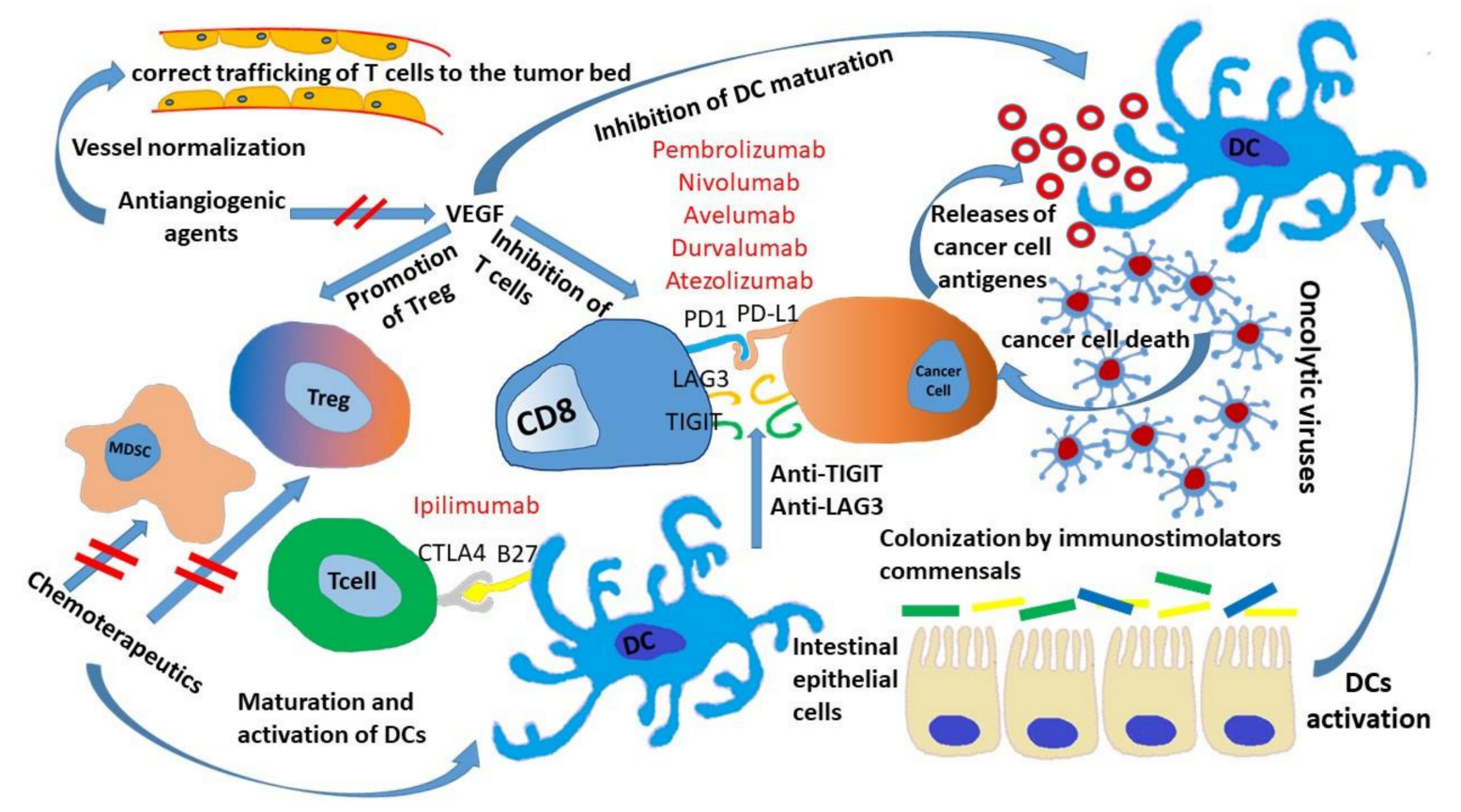

Figure 2. Summarizes the mechanisms implicated in improving the efficacy of immune checkpoint inhibitors (ICIs): The influence of microbiota on dendritic cell (DC) maturation and activation; the correct trafficking of $\mathrm{T}$ cells to the tumor bed due to the normalization of endothelium by anti-angiogenic drugs and the VEGF immunosuppressive activity; the impact of chemotherapy on immunosuppressive cells and on DC maturation; release of damaged molecular patterns after oncolytic viruses induce tumor cell lysis.

In conclusion, there is evidence supporting the relationship between some bacterial species and the enhanced response to ICIs (i.e., Ruminococaceae family of the Firmicutes phylum as Firmicutesprausnitzii) [19-21]. Similarly, other intestine microbiome components (i.e., Bacterioides and Firmicutes phylum) have been associated with a lack of response to immune checkpoint 
blockade [19-21]. Data concerning Firmicutes (Roseburia, Streptococcus) [20,22] and other B. (i.e., Alistipes, Porphyromonaspasteri, and C. aerofaciens) are still not univocal [14,21,22]. It is interesting to note how different bacteria are beneficial in different types of cancer. The differences in the methods used for sample feces and the analysis of the intestinal microbiome, the databases used for analysis, and the populations with both dietary and microbiotic differences are responsible for the ambiguity of these data. These heterogeneous results make it difficult to interpret the reason for such different data. In particular, it is still unclear why different microbiota improve ICI in different types of cancer. Clinical trials are underway to define the possible role of the microbiota in improving the ICI response.

\section{Chemotherapeutics Sensitizing Tumor to ICIs}

Recently, the combination of immunotherapy and chemotherapy has been approved for the treatment of both metastatic and locally advanced NSCLC [1-3]. Chemotherapy not only achieves an ulterior efficacy to immunotherapy but it also acts in a synergistic manner in two significant ways: (a) Induction of immunogenic cell death as part of its independent therapeutic effects and (b) disruption strategies used by neoplastic cells to evade immune response. The first process involves the release of tumor antigens and the emission of danger-associated molecular patterns within tumor microenvironment during cell death. At the same time, chemotherapy decreases the number of immunosuppressive cells in the microenvironment including Tregs and MDSCs, increases the number of cytotoxic T lymphocytes (CTLs) and promotes maturation and activation of DCs (Figure 2). In addition, chemotherapeutics modifies the levels of several cytokines, down-regulates immune suppressive cytokines (i.e., transforming growth factor- $\beta$ (TGF $\beta$ ) and IL10), and up-regulates cytokines promoting tumor immunity (i.e., tumor necrosis factor- $\alpha$ (TNF- $\alpha$ ), IL-2, and interferon (IFN)- $\gamma$ ) [23].

As far as ICIs are concerned, preclinical models showed that autochthonous tumors that lacked CTLs infiltration were resistant to these agents, while on the contrary the exposure to appropriately selected immunogenic chemotherapeutics induces CTLs tumor infiltration, sensitizing tumor to ICIs. In the mouse model of lung adenocarcinoma, refractory to an anti-PD- 1 and anti-CTLA- 4 mAb combination therapy, the use of oxaliplatin in combination with a low-dose of cyclophosphamide increased the lung CTLs/Treg cell ratio sensitizing the tumor to ICIs [24]. Similarly, oxaliplatin increased the amounts of CTLs and activated DCs in a murine colorectal cancer, enhancing the efficacy of a PD-L1 trap [25]. A low-dose of cyclophosphamide combined with an anti-PD1 synergistically induced antigen-specific immunity and the infiltration of $\mathrm{CD} 8+$ and $\mathrm{CD} 4+\mathrm{FoxP}^{-} \mathrm{T}$ cells as well as it induced the suppression of the CD4+ CD25+ FoxP3+ regulatory $\mathrm{T}$ cell function, thus resulting in the increase of tumor-free survival in a model of cervical cancer [26,27]. According to these studies, 5 -fluoruracil (5-FU) increased tumor immunity in a mouse model by renal cell xenograft through an increase of CTL infiltration mediated by the High Mobility Group Box 1 (HMGB1). Interestingly, a combined 5-FU and anti-PD-L1 treatment significantly improved the relationship between CTL and MDSCs compared to5-FU and anti-PD-L1 single treatments with a longer OS [28].

On the other hand, several chemotherapeutics have been shown to induce an up-regulation of PD-L1 expression, as a possible mechanism of chemotherapy immune suppression. However, the increase of PD-L1 expression may support the synergism between chemotherapy and immunotherapy targeting the PD-L1/PD-1 axis. 5-FU demonstrated up-regulation of PD-L1 in two preclinical studies evaluating colorectal cancer patients [25,29]. Similarly, the administration of trabectedin induced the IFN- $\gamma$-dependent PD-L1 expression within a tumor in a murine model of ovarian cancer [30]. Others drugs able to up-regulate PD-L1 expression in ovarian cancer models are paclitaxel, carboplatin, cisplatin, gemcitabine, and capecitabine [31].Interestingly, Peng J et al. showed, from a collection of cancer cells from ovarian cancer patients with massive ascites, that the expression of PD-L1 increased 5-fold on day four after combined paclitaxel and carboplatin therapy and decreased to pre-treatment levels on day 11, demonstrating the reversibility of PD-L1 expression induced by chemotherapy [31]. Finally, the evaluation of 150 specimens of patients with ovarian cancer treated with neoadjuvant chemotherapy showed the up-regulation of PD-L1 [32]. 
Several clinical trials are evaluating the combination of chemotherapy with ICIs, but in the majority of these, chemotherapy and chemotherapeuticsis administered concurrently and at full doses. Only a few trials are focused on the role of chemotherapeutics as sensitizers for immunotherapy, exploring the optimal dose, or the sequence of administration, while preclinical data have shown that these parameters might affect the results.

An open, multi-center, single-arm label, Phase $\mathrm{Ib} / \mathrm{II}$, evaluated the daily metronomic dose of $50 \mathrm{mg}$ of cyclophosphamide without interruption of administration, $10 \mathrm{mg} / \mathrm{kg}$ of avelumab on day one and every two weeks until progression, and a single fraction of 8Gy radiotherapy in pretreated head and neck cancer patients, showing noun acceptable toxicity [27]. A study concerning metastatic patients with triple negative breast cancer (TNBC) patients investigated induction therapy with various types of chemotherapy [33]. For the induction phase, low doses of chemotherapy were given for two weeks: $50 \mathrm{mg}$ daily cyclophosphamide, twice $40 \mathrm{mg} / \mathrm{m}^{2}$ cisplatin or twice $15 \mathrm{mg}$ doxorubicin. Response rates with chemotherapy appear higher in the cohorts where low-dose chemotherapy was used as induction, compared with nivolumab alone. Conversely, an immunotherapy induction phase may also be useful. An induction phase with durvalumab followed by combination therapy of nab-paclitaxel weekly for 12 weeks followed by four cycles of combined therapy with epirubicin and cyclophosphamide was evaluated in patients with TNBC, resulting in a higher pathological CR rate when compared with chemotherapy alone (53.4\% versus $44.2 \%$, respectively) [34].

Other trials evaluating the combination of metronomic chemotherapy with ICIs [35] or the impact of chemotherapy on TMB [36] are underway. Future studies should evaluate drugs capable of inducing immune cell death and CTLs tumor microenvironment infiltration, optimizing ICI integration with chemotherapy.

\section{ICIs and Antiangiogenic Drugs}

The vascular network with its specific components (endothelial cells, pericytes, growth factors, and receptors) plays a key role in the regulation of inflammatory response, wound healing, and immune surveillance. Antigen-primed T cells require a healthy endothelium for the trafficking to tissue districts and the cell-to-cell cross-talk during the priming and effector phase of the immune response. The transit of immune cells in the tumor plays a critical role in the outcome of immunotherapeutic strategies, similarly to classical chemotherapeutic drugs. In particular, a normalized endothelium ensures the correct trafficking of $\mathrm{T}$ cells to the tumor bed [37]. In fact, tumor angiogenesis contributes to the escape of the immune tumor through the immunosuppressive activity exerted by VEGF, PGE2, IL-10, and tumor hypoxia. In particular, VEGF acts through both the inhibition of lymphocyte adhesion to activated endothelial cells and the systemic effect on immune-regulatory cell function, including the suppression of DCs maturation, the inhibition of T cell development, and the increase of inhibitory immune cells [38] (Figure 2). Therefore, the possibility of administering ICIs during an anti-angiogenic treatment has been studied in different types of cancers according to the hypothesis that anti-angiogenic drug-induced normalization of the vessels may improve immunotherapeutic strategies. On the other hand, ICI activation of Th1 cells blocked vessel normalization, suggesting the existence of a mutually regulatory circuit [39].

In a phase II study, 46 patients with metastatic melanoma were treated in four dosing cohorts of ipilimumab ( 3 or $10 \mathrm{mg} / \mathrm{kg}$ ) with four doses at three-week intervals and then every 12 weeks in combination with bevacizumab ( 7.5 or $15 \mathrm{mg} / \mathrm{kg}$ every three weeks). Eight partial responses and 22 stable diseases were observed, with a disease-control rate of $67.4 \%$ and a median OS of 25.1 months [40]. Bevacizumab has been evaluated also in combination with ICI targeting the PD-1/PD-L1 axis in a phase II study considering HER2-negative advanced breast cancer patients. The combination of nivolumab, paclitaxel, and bevacizumab showed an overall response rate ORR of $70 \%$ [41]. The same combination demonstrated clinical activity in women with recurrent ovarian cancer, which showed a global confirmed response rate of $21 \%$ and a median PFS of 9.4 months [42]. In another study patients with pre-treated NSCLC with platinum-based first-line chemotherapy received nivolumab 
plus bevacizumab as maintenance therapy with $1-\mathrm{yr}$ OS rate of $75 \%$ and a manageable toxicity profile [43]. Recently, the phase III IM power 150 trial showed no new safety signals of the combination of atezolizumab plus bevacizumab, carboplatin, and taxol in first-line non-squamous NSCLC patients with a median OS of 20.5 months [2]. Interestingly, the first randomized phase III trial of a PD-L1/PD-1 pathway inhibitor combined with bevacizumab in first-line mRCC showed longer PFS for atezolizumab plus bevacizumab compared to sunitinb in PD-L1+ patients [44]. The safety and efficacy of a combined treatment of bevacizumab with atezolizumab was assessed in pre-treated patients with metastatic colon rectal cancer (MCRC), or in oxaliplatin-naïve patients in conjunction with FOLFOX (fluorouracil, folinic acid, leucovorin, and oxaliplatin), with an ORR of $44 \%$ in the combination group. In a phase $1 \mathrm{a} / \mathrm{b}$ study [45] concerning patients with gastric or gastroesophageal junction (G/GEJ), NSCLC, UC, or biliary tract cancer (BTC), the combination of ramucirumab $(10 \mathrm{mg} / \mathrm{kg})$ with pembrolizumab (200 $\mathrm{mg}$ on the first day of $\mathrm{q} 3 \mathrm{w}$ ) showed a disease control rate DCR of $85 \%$ with no relevant toxicity [46]. Regarding antiangiogenic TKIs, the combination of nivolumab and either pazopanib or sunitinib has been evaluated in mRCC pre-treated with at least one previous systemic therapy. An 45\% ORR was demonstrated in the nivolumab plus pazopanib arm, compared to $52 \%$ in the nivolumab plus sunitinib arm, with a manageable safety profile. These combination approaches might benefit patients with poor prognosis, such as those with a low probability to respond to ICI monotherapy (i.e., refractory to patients on first-line therapy or showing PDL1-negative tumors) [47]. Considering the potential role of antiangiogenenic therapies of changing a cold tumor into a hot one, several trials are currently underway investigating other combinations of antiangiogenic agents and ICIs.

\section{Strategies Involving Other Co-Inhibitor Receptors}

The encouraging outcome obtained by the co-inhibitory receptors CTLA-4 and PD-1 prompted the research of additional co-inhibitory molecules. T cell immunoglobulin and immune-receptor tyrosine-based inhibitory motif domain (TIGIT) is a newly identified co-inhibitory receptor expressed by Tregs, activated T cells, and natural killer (NK) cells [48]. TIGIT expression is elevated on CD8 ${ }^{+}$TILs and Tregs in a variety of tumors, as well as the expression of its three ligands, namely CD155, CD112, and CD11 3 [49]. Moreover, TIGT and PD-1 are co-expressed and up-regulated on TILs. Dual blockade of two immune checkpoints enhances function of TILs resulting in a significant tumor rejection, as demonstrated by the combination of anti-CTLA-4 with anti-PD-1/PD-L1.Anti-PD-1 and anti-TIGT dual therapy significantly improved survival compared to control and monotherapy in a murine glioblastoma (GBM) model. Clinically, TIGIT expression on tumor-infiltrating lymphocytes was shown to be elevated in GBM samples, suggesting that the TIGIT pathway may be a valuable therapeutic target [50]. A phase II, randomized, blinded, placebo-controlled trial is currently underway that considersMTIG7192A, an anti-TIGIT antibody, in combination with atezolizumab patients with chemotherapy-naïve NSCLC [51].

Lymphocyte activation gene-3 (LAG3), an immune checkpoint up-regulated on activated T cells, Treg, and NK cells in different types of cancer, is required for the maintenance of Treg suppressive function. LAG3 blocks either by soluble LAG3 immunoglobulin or antibodies have shown efficacy in the antitumor response. Similarly, to TIGT, LAG3 coexisted and upregulated with PD-1 on TILs [52]. According to preclinical data showing a significant increase in the activity of dual blockade of LAG3 and PD-1 [53], numerous clinical trials are underway with the aim of translating this combination modality into clinical practice.

An open-label phase 1/2a trial evaluating BMS-986016, an experimentalanti-LAG-3, in combination with nivolumab in patients with advanced melanoma previously treated with anti-PD-1/PD-L1 therapy $(n=55)$. ORR was $12.5 \%$ in evaluable patients $(n=48)$. The expression of LAG-3in at least $1 \%$ $(n=25)$ of tumor-associated immune cells within the tumor margin was associated with an almost triple improvement in ORRs compared to patients without LAG-3 expression $(n=14)(20 \%$ and $7.1 \%$, respectively) [54]. LAG525, a humanized IgG4 mAbs capable of blocking the binding of LAG-3 to class IIMHC, is being studied in a phase I/II study in combination with an anti-PD1 treatment. 
Common adverse events ( $\geq 10 \%)$ were fatigue $(10 \%)$ for LAG525 alone and fatigue (18\%), diarrhea (15\%), and nausea $(12 \%)$ in the combination group. LAG525 plus the anti-PD1 spartalizumab drug led to durable RECIST responses (11 PR, 1 CR) in a variety of solid tumors, including mesothelioma (2/8 pts) and triple-negative breast cancer (TNBC) ( $2 / 5$ pts). In TNBC tumor biopsies, a tendency to convert immuno-cooled biomarker profiles to immune-activated has been reported [55]. T cell immunoglobulin containing the mucin domain 3 (TIM-3) is widely expressed on helper $1 \mathrm{~T}$ cells, CD8+ lymphocytes, Treg, DCs, NK cells, and monocytes. Similarly, to TIGIT and LAG3, the high expression of TIM-3 and PD-1 is observed in the tumor microenvironment, in particular on TIL and Treg, suggesting the possible re-establishing of T cell function through the targeting of TIM-3 and PD-1 [56]. A phase 1 study is evaluating the anti-TIM-3 antibody (T cell immunoglobulin and protein-containing mucin 3) TSR-022 as monotherapy and in combination with an anti-PD-1 antibody, in pre-treated patients with advanced solid tumors [57].

\section{Oncolytic Virus and ICIs}

The oncolytic virus vectors are designed to have a high tumor tropism, maximize cancer killing effects and minimized a mage to surrounding normal tissue. It is interesting to note that these viruses not only facilitate the lysis of tumor cells, but also cause a strong change in the tumor immune microenvironment. In particular, oncolytic viruses transfer the genes encoding IFN- $\alpha$, GM-CSF, and others cytokines that induce tumor-specific immunity by promoting DC maturation and function. On the other hand, tumor cell lysis induced by oncolytic viruses determines the release of damage-associated molecular patterns (DAMPS) that include cell surface proteins, membrane proteins, and nucleic acids (Figure 3) [58,59].

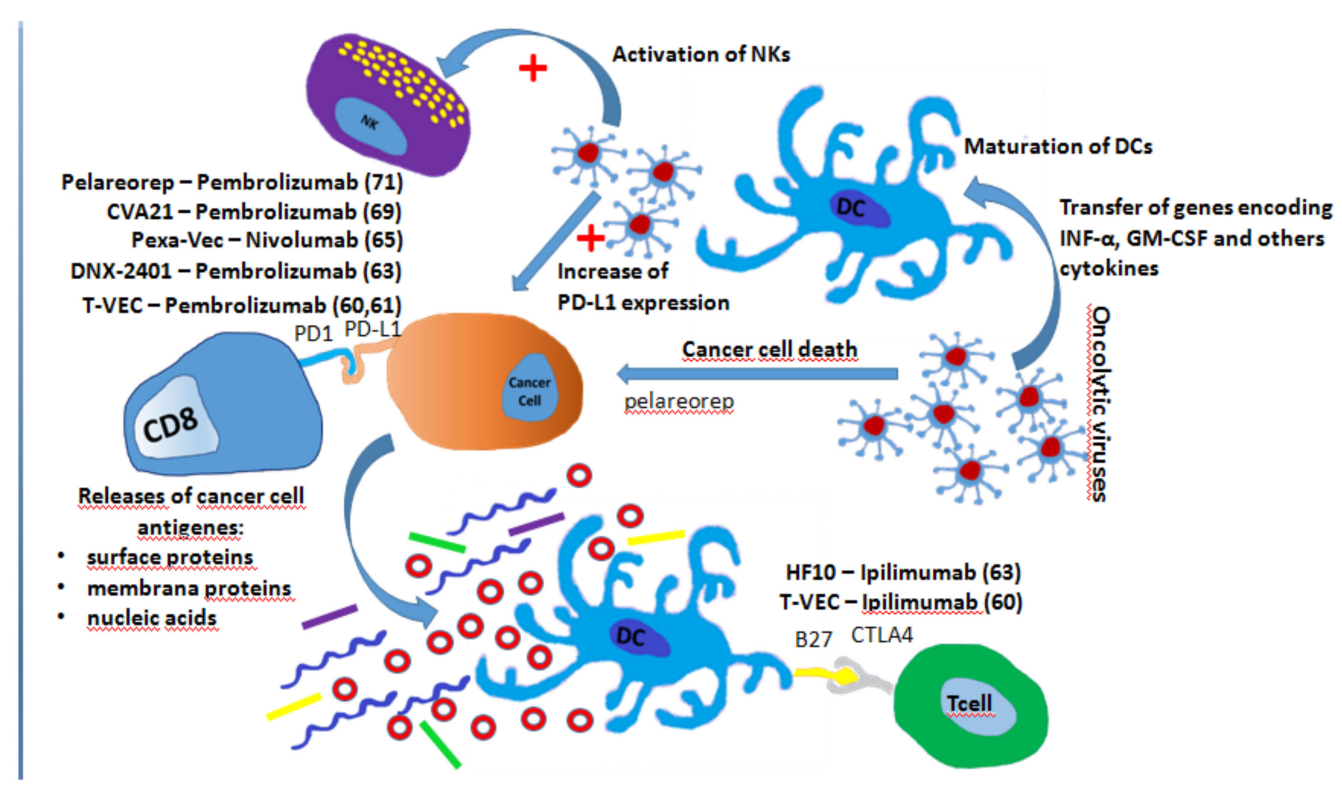

Figure 3. Summary of the mechanisms involved in improving of ICI efficacy by oncolytic viruses: Release of damage-associated molecular patterns after tumor cell lysis, transfer of genes encoding INF- $\alpha$, GM-CSF and others cytokines, DC maturation and activation, natural killer (NK) cell activation, and increase in PD-L1 expression. The main studies evaluating the combination of oncolytic viruses are also reported.

Talimogene Laherparepvec (T-VEC) replicates within tumors and produces GM-CSF, resulting in a first-rate FDA-approved intralesional oncolytic immune therapy for stage IIIb and IV melanoma. A recent phase II trial comparing ipilimumab plus T-VEC with ipilimumab alone showed that the ORR in the combination arm was significantly higher than in the monotherapy arm (39\% vs. $18 \%$; $p<0.02$ ) [60]. Distant non-injection sites demonstrated an adjuvant effect with a reduction in visceral 
lesions size in $52 \%$ of patients in the combination arm versus only $2 \%$ of the patients in the ipilimumab arm. T-Vec has been also tested in patients with melanoma in combination with pembrolizumab in a phase $\mathrm{Ib}$ study. No dose-limiting toxicity was observed with an ORR of $62 \%$ and a CRR of $33 \%$ [58]. A phase III trial is underway [61]. It is interesting to note that an analysis performed prior to the administration of anti-PD1 antibodies showed that T-VEC increased the PD-L1 expression and inflammation distant from the injection sites. HF 10, another virus included in the HSV family, in combination with ipilimumab showed in a phase II clinical trial regarding stage IIIB/IIIC or IV unresectable melanoma a DCR of $68 \%$ without disease limiting toxicity [62]. An oncolytic adenovirus competent for replication with tumor selectivity, namely Tasadenoturev (DNX-2401), was able to overcome the exhaustion of $\mathrm{T}$ cells demonstrating a reduction in tumor size in a phase I study for patients with recurrent GBM. A phase II study employing DNX-2401 and pembrolizumab in GBM progressed after initial therapy is currently underway [63]. Another group of oncolytic viruses is represented by vaccinia viruses, members of the Poxviridae family, which are suitable for transgene insertion. Pexa-Vec targeted tumor-associated endothelial cells resulting in vascular disruption and oncolysis [64]. A single dose of Pexa-Vec intravenously demonstrated activation of NK, CD4/CD8 $\mathrm{T}$ cells, and antigen presenting cells in surgically treated liver metastases. The combination of Pexa-Vec and nivolumab is under investigation for the treatment of liver tumors [65]. Furthermore, the combination of Pexa-Vec with other ICIs is being evaluated in colorectal cancer and other advanced tumors, respectively [66,67]. When speaking about Coxackieviruses, CVA 21 is able to increase infiltration of immune cells and checkpoint molecules, several clinical trials concerning the combination of CVA 21 with ICIs are ongoing [68]. In particular, in the CAPRA clinical trial, patients who receive multiple intratumoral injections of CVA 21 and pembrolizumab showed an ORR of 73\% [69]. Finally, the reoviruses, characterized by icosahedral capsid and double-stranded RNA genomes, have been shown to increase cytotoxic T cells infiltrating the CD8+tumor in an $\mathrm{Ib}$ phase concerning GBM patients undergoing debulking neurosurgery [70]. A clinical trial [71] is underway evaluating the use of a reovirus, namely pelareorep in combination with pembrolizumab and chemotherapy in patients with recurrent metastatic pancreatic cancers.

\section{Small Molecule Inhibitors and ICIs}

Various evidence suggests that small molecule inhibitors could improve host-tumor interactions, improving antigen expression and the immune response against tumor cells [72]. Several small molecules in combination with ICIs have been studied for the treatment of different types of tumor histotypes (Table 2).

The first combination of small molecule inhibitors and ICIs have been evaluated in melanoma. In particular, since the administration of BRAFi/MEKi represents a standard treatment of metastatic BRAFV600E melanoma, the possibility that this association would be improved by ICIs has been evaluated. It has been demonstrated that BRAF inhibition is associated with enhanced melanoma antigen expression [73-75]. Moreover, selective BRAF inhibitors induce marked $\mathrm{T}$ cell infiltration in human metastatic melanoma [74], with an up-regulation of PD-L1 in the tumor microenvironment [72,74]. Nevertheless, the benefit of this combination in preclinical models has been modest [76-79]. In particular, in a mouse model of syngeneic BRAF ${ }^{\mathrm{V} 600 \mathrm{E}}$ driven melanoma, the combination of dabrafenib and trametinib with pmel-1 adoptive cell transfer showed a complete tumor regression with increased $\mathrm{T}$ cell infiltration in tumors and improved in vivo cytotoxicity. Single agent dabrafenib increased the number of tumor-associated macrophages and Tregs in tumors that conversely decreased with the addition of trametinib. The combination of BRAFi/MEKi and ICI induced either an increased expression of the melanosomal antigens and MHC or the global immune-related gene up-regulation. Moreover, a combination of dabrafenib and trametinib with anti-PD1 therapy in SM1 tumors led to a greater anti-tumor effect compared to the results obtained with the only small molecules combination [80]. 
Table 2. Small Molecule Inhibitors and ICIs.

\begin{tabular}{|c|c|c|c|c|c|}
\hline Small Molecule Enhancer & ICI & Cancer & Study Design & Results/Enhancing & Reference \\
\hline BRAFi & Not associated & Melanoma & In vitro & BRAF inhibition enhance melanoma antigen expression & Wilmott, 2013. [72] \\
\hline Selective BRAF inhibitors & Not associated & Melanoma & In vitro & $\begin{array}{l}\text { Induction of Tcell infiltration into human metastatic melanoma } \\
\text { Up-regulation of PD-L1 in tumor microenvironment }\end{array}$ & Wilmott, 2012. [74] \\
\hline Dabrafenib and trametinib & $\begin{array}{l}\text { (pmel-1 adoptive cell } \\
\text { transfer) }\end{array}$ & $\begin{array}{l}\text { BRAFV600E driven } \\
\text { melanoma }\end{array}$ & In vivo-mouse model & $\begin{array}{l}\text { Complete tumor regression with increased } \mathrm{T} \text { cell infiltration } \\
\text { into tumors and improved in vivo cytotoxicity }\end{array}$ & Cooper, 2014. [79] \\
\hline Dabrafenib and trametinib & anti-PD1 & SM1 tumors (melanoma) & In vivo-mouse model & $\begin{array}{l}\text { Superior anti-tumor effect compared to the results obtained } \\
\text { with the only small molecules combination }\end{array}$ & Hu-Lieskovan, 2015. [80] \\
\hline Vemurafenib & Ipilimumab & Melanoma & Phase 1 trial & Stopped after one month due to liver toxicity & Ribas, 2013. [81] \\
\hline Dabrafenib, trametinib & Ipilimumab & Melanoma & Phase 1 trial & Stopped due to excessive colon toxicity & Minor, 2015. [82] \\
\hline Dabrafenib & Ipilimumab & BRAF-mutated melanoma & Phase 1 trial & $\begin{array}{c}\text { ORR of } 69 \% \\
\text { Good safety profile }\end{array}$ & Puzanov, 2014. [83] \\
\hline Dabrafenib and trametinib & pembrolizumab & BRAF-mutated melanoma & $\begin{array}{l}\text { KEYNOTE-022, an ongoing } \\
\text { phase I/II trial }\end{array}$ & ORR of $60 \%(n=9 \mathrm{PR}, n=2 \mathrm{SD}, n=3 \mathrm{PD})$ & $\begin{array}{l}\text { NCT02130466, [84] } \\
\text { Ribas, 2016. [85] }\end{array}$ \\
\hline Vemurafenib (V) & Atezolizumab (A) & Melanoma & $\begin{array}{l}\text { Phase Ib trial (V-run in vs. } \\
\text { concurrent V-A) }\end{array}$ & $\begin{array}{l}\text { Higher ORR was seen with V run-in than with concurrent A + } \\
\text { V start }\end{array}$ & Sullivan, 2016. [86] \\
\hline Vemurafenib, and cobimetinib & Atezolizumab & $\mathrm{BRAF}^{\mathrm{V} 600}$-mutant melanoma & Phase I/II trial & Manageable safety profile and promising antitumor activity & NCT01656642. [84] \\
\hline imatinib & Not associated & GIST & In vitro study & Reduction of Treg immunosuppressive function & Larmonier, 2008. [87] \\
\hline Imatinib & Not associated & GIST & In vivo study & PFS correlated with IFN- $\gamma$ secretion by NK cells & Ménard, 2009. [88] \\
\hline Imatinib & Not associated & GIST & In vivo-mouse model & $\begin{array}{l}\text { Activated CD8+ T cells and induced Treg apoptosis in tumor } \\
\text { sample }\end{array}$ & Balachandran, 2011. [89] \\
\hline Imatinib & $\begin{array}{l}\text { Anti-PD-1 (RMP1-14) or } \\
\text { anti-PD-L1 (10F.9G2) }\end{array}$ & GIST & In vivo-mouse model & $\begin{array}{c}\text { Increased antitumor effects by enhancing cytotoxic } \mathrm{T} \text { cell } \\
\text { effector function }\end{array}$ & Seifert, 2017. [90] \\
\hline Imatinib & Ipilimumab & $\begin{array}{l}\text { GIST and other c-Kit positive } \\
\text { solid cancers }\end{array}$ & Phase 1 trial & $\begin{array}{l}\text { Manageable safety profile in multiple tumor types. } \\
\text { Low activity with no clear signal for synergy in escalation or } \\
\text { GIST expansion cohorts }\end{array}$ & $\begin{array}{l}\text { NCT01738139, [91] } \\
\text { Reilley, 2017. [92] }\end{array}$ \\
\hline Rapamycin & Not associated & Oral cancer & In vivo-mouse model & $\begin{array}{l}\text { Reduction of tumor growth through } \\
\text { CD8-activity }\end{array}$ & Cash, 2015. [93] \\
\hline Rapamycin & Not associated & Oral cancer & In vivo-mouse model & $\begin{array}{l}\text { Enhancing of IFN } \gamma \text { production by peripheral and } \\
\text { tumor-infiltrating CD8 T cells }\end{array}$ & Moore, 2016. [94] \\
\hline Rapamycin & PD-L1 mAb & Oral cancer & In vivo-mouse model & $\begin{array}{l}\text { Activation of CD8 T cells in tumor infiltration increased by the } \\
\text { addition of rapamycin }\end{array}$ & Moore, 2016. [94] \\
\hline CDK4/6 inhibitor & Not associated & Breast cancer & $\begin{array}{c}\text { In vivo-mouse model/blood } \\
\text { sample patients }\end{array}$ & Anti-tumor immunity through proliferation of Tregs & Goel, 2017. [95] \\
\hline CDK4/6 inhibitor & anti-PD-1 & Breast cancer & In vivo—-mouse model & $\begin{array}{l}\text { Enhancing of tumor regression and dramatically improving of } \\
\text { OS }\end{array}$ & Zhang, 2018. [96] \\
\hline $\begin{array}{l}\text { CDK4/6 inhibitor and PI3K } \\
\text { antagonist }\end{array}$ & $\begin{array}{l}\text { Anti PD- } 1 \text { and anti } \\
\text { CTLA-4 }\end{array}$ & Triple negative breast cancer & In vivo-mouse model & $\begin{array}{l}\text { Inhibition induced complete and durable regressions ( }>\text { one } \\
\text { year) of breast tumors in in vivo models. }\end{array}$ & Teo, 2017. [97] \\
\hline
\end{tabular}


The first phase 1 trial evaluating the role of ipilimumab in combination with vemurafenib was stopped after one month due to liver toxicity [81]. Another phase 1 study evaluated the safety of the combination of dabrafenib, trametinib, and ipilimumab. This study was also stopped due to excessive colon toxicity [82]. A combination of dabrafenib and ipilimumab demonstrated an ORR of $69 \%$ in the 26 BRAF-mutated patients with a good safety profile [83]. The KEYNOTE-022, an ongoing phase I/II trial [98], is evaluating the combination of pembrolizumab with dabrafenib and trametinib. Preliminary data on 15 patients enrolled across dose determination and dose confirmation arms showed a safety profile and an ORR of $60 \%(n=9 \mathrm{PR}, n=2 \mathrm{SD}, n=3 \mathrm{PD})$ [85]. A phase Ib study is investigating vemurafenib and atezolizumab combination and comparing this combination concurrently or after a run-in period with vemurafenib alone [99]. It was demonstrated that the vemurafenib run-in showed a higher ORR than concomitant atezolizumab plus the onset of vemurafenib. The combination of atezolizumab, vemurafenib, and cobimetinib in this subgroup of patients is being investigated [84]. Preliminary results confirmed that this combination has a manageable safety profile with a promising antitumor activity in patients with $\mathrm{BRAF}^{\mathrm{V} 600}$-mutant metastatic melanoma [86].

Also, in gastrointestinal stromal tumors (GIST), preclinical studies demonstrated that imatinib in combination with ICIs should improve the immune response. It is well known that this drug induces NK cells activity through DCs in several cancers $[100,101]$. Furthermore, in an in vitro study, imatinib reduced the Treg immunosuppressive function and the FoxP3 expression with the inhibition of phosphorylation of both ZAP70 and LAT, impairing their immunosuppressive function [87]. Moreover, PFS correlated with IFN- $\gamma$ secretion by NK cells in patients affected by GIST treated with imatinib [88]. In a mouse model of spontaneous GIST, Balachandran et al. demonstrated that the immune system substantially contributed to the anti-tumor effects of imatinib. In fact, it activated CD8+ $\mathrm{T}$ cells and induced Treg apoptosis in the tumor sample by reducing immunosuppressive enzyme indoleamine 2,3-dioxygenase (IDO) [89]. In a more recent study, PD-1 was expressed more on T cells in imatinib-treated human GISTs as compared to untreated patients. Imatinib inhibited the upregulation of PD-L1 through IFN $\gamma$ in human GIST cell lines. In a GIST mouse model, imatinib down-regulated IFN $\gamma$ related genes and reduced the PD-L1 expression on tumor cells. Moreover, PD-1 or PD-L1 blockade without imatinib achieved no response in GIST mouse model. On the contrary, association of ICIs and imatinib increased antitumor effects by enhancing cytotoxic T cell effector function [90].

A current phase I study is evaluating the effect of a combination of ipilimumab and imatinib GIST positive solid cancers and other-Kit [91]. Preliminary results have shown that this combination is safe on most types of tumors. Nevertheless, low activity without a clear synergy signal is observed in GIST expansion or escalation cohorts [92].

It is interesting to note that a combination of small molecules and ICIs have been evaluated in a mouse model of oral cancer. In this neoplasia, both activation of PI3K/mTOR and MEK/ERK pathways promoted the immunosuppressive tumor microenvironment [102]. In an immunogenic model of cancer of the oral cavity, rapamycin reduced tumor growth in a CD8-dependent manner [93]. More recently, Moore et al. [94] demonstrated that rapamycin improved IFN $\gamma$ production by peripheral and tumor-infiltrating CD8 T cells in a mouse model of oral cancer. Furthermore, antitumor efficacy was enhanced by the CD8 T cell but not by NK cell. Non-inflamed tumor models, which represent the low level of response to immune therapies, did not induce T cell or NK CD8 cell-mediated antitumor immunity when treated with combinations of targeted and ICIs. In other models, antitumor immune responses to PD-L1 mAb treatment were enhanced when treated with mTOR inhibitors. These data suggested that a combination of mTOR and ICIs inhibitors should be evaluated in clinical trials setting.

There are few preclinical studies considering small molecules inhibitors and ICIs combinations in breast cancer patients. In both murine models and breast cancer patients, CDK4/6 inhibition induced anti-tumor immunity through suppression of Tregs and contributing to anticancer effects [95]. Since cyclin D-CDK4 regulated PD-L1 protein expression, inhibition of CDK4/6 in vivo increases PD-L1 protein levels through inhibition of cyclin D-CDK4. Combination of CDK4/6 inhibitor and anti-PD-1 immunotherapy enhanced tumor regression and dramatically improved OS rates in mouse breast 
cancer models [96]. Teo et al. demonstrated that PI3K antagonist and CDK4/6 inhibition significantly increased tumor immunogenicity through generating immunogenic cell death in triple negative breast cancer model. Moreover, this combination significantly increased tumor-infiltrating $\mathrm{T}$ cell activation and cytotoxicity with reduction of immune-suppressive myeloid-derived suppressor cells. Association of immune checkpoints PD-1, CTLA-4 to PI3K antagonist and CDK4/6 inhibition induced complete and durable regressions ( $>$ one year) of breast tumors in in vivo models [97].

In the era of precision medicine, several small molecules have been demonstrated to be active in targeting specific pathways leading to apoptosis of cancer cells with impressive results in anti-cancer treatment. In addition, these molecules appear capable of increasing tumor immunogenicity through the increase of cancer antigens and the activation of cytotoxic activity of CD8 cells leading to an increased putative activity of ICIs when associated in concomitant or sequential therapeutic schedules.

\section{Conclusions}

This systematic review has summarized the current study of the main classes of drugs which improve the activity of the ICIs. The assessment of drugs able to modify the tumor immune microenvironment in addition to ICIs is a field of research, which is currently undergoing a significant escalation. Despite the encouraging results, only chemotherapy has currently adhered to clinical practice for this specific use. Curiously, most of these molecules are characterized by a high level of safety and already consolidated clinical use for indications other than those considered in this study. These features should allow for the possibility of undertaking more extensive and well-designed studies. At the same time, the possibility of new side effects due to the combinatorial strategies or the potential amplification of the well-known ICIs side effects [103,104] should be carefully monitored.

Funding: This research received no external funding.

Conflicts of Interest: The Authors declare no conflicts of interests.

\section{References}

1. Gandhi, L.; Rodríguez-Abreu, D.; Gadgeel, S.; Esteban, E.; Felip, E.; De Angelis, F.; Domine, M.; Clingan, P.; Hochmair, M.J.; Powell, S.F.; et al. Pembrolizumab plus Chemotherapy in Metastatic Non-Small-Cell Lung Cancer. N. Engl. J. Med. 2018, 378, 2078-2092. [CrossRef]

2. Socinski, M.A.; Jotte, R.M.; Cappuzzo, F.; Orlandi, F.; Stroyakovskiy, D.; Nogami, N.; Rodríguez-Abreu, D.; Moro-Sibilot, D.; Thomas, C.A.; Barlesi, F.; et al. Atezolizumab for First-Line Treatment of Metastatic Nonsquamous NSCLC. N. Engl. J. Med. 2018, 378, 2288-2301. [CrossRef]

3. Antonia, S.J.; Villegas, A.; Daniel, D.; Vicente, D.; Murakami, S.; Hui, R.; Yokoi, T.; Chiappori, A.; Lee, K.H.; de Wit, M.; et al. Durvalumab after Chemoradiotherapy in Stage III Non-Small-Cell Lung Cancer. N. Engl. J. Med. 2017, 377, 1919-1929. [CrossRef]

4. Wolchok, J.D.; Chiarion-Sileni, V.; Gonzalez, R.; Rutkowski, P.; Grob, J.J.; Cowey, C.L.; Lao, C.D.; Wagstaff, J.; Schadendorf, D.; Ferrucci, P.F.; et al. Overall Survival with Combined Nivolumab and Ipilimumab in Advanced Melanoma. N. Engl. J. Med. 2017, 377, 1345-1356. [CrossRef] [PubMed]

5. Cella, D.; Grünwald, V.; Escudier, B.; Hammers, H.J.; George, S.; Nathan, P.; Grimm, M.O.; Rini, B.I.; Doan, J.; Ivanescu, C.; et al. Patient-reported outcomes of patients with advancedrenalcell carcinoma treated withnivolumabplusipilimumabversussunitinib (CheckMate214): A randomised, phase 3 trial. Lancet Oncol. 2019, 20, 297-310. [CrossRef]

6. Balar, A.V.; Castellano, D.; O’Donnell, P.H.; Grivas, P.; Vuky, J.; Powles, T.; Plimack, E.R.; Hahn, N.M.; de Wit, R.; Pang, L.; et al. First-linepembrolizumabin cisplatin-ineligible patients with locally advanced and unresectable or metastaticurothelialcancer (KEYNOTE-052): A multicentre, single-arm, phase 2 study. Lancet Oncol. 2017, 18, 1483-1492. [CrossRef]

7. Borghaei, H.; Paz-Ares, L.; Horn, L.; Spigel, D.R.; Steins, M.; Ready, N.E.; Chow, L.Q.; Vokes, E.E.; Felip, E.; Holgado, E.; et al. Nivolumab versus Docetaxel in Advanced Nonsquamous Non-Small-Cell Lung Cancer. N. Engl. J. Med. 2015, 373, 1627-1639. [CrossRef] 
8. Kanjanapan, Y.; Day, D.; Wang, L.; Al-Sawaihey, H.; Abbas, E.; Namini, A.; Siu, L.L.; Hansen, A.; Razak, A.A.; Spreafico, A.; et al. Hyperprogressive disease in early-phase immunotherapy trials: Clinical predictors and association with immune-related toxicities. Cancer 2019, 125, 1341-1349. [CrossRef] [PubMed]

9. Chuong, M.; Chang, E.T.; Choi, E.Y.; Mahmood, J.; Lapidus, R.G.; Davila, E.; Carrier, F. Exploring the Concept of Radiation "Booster Shot" in Combination with an Anti-PD-L1 mAb to Enhance Anti-Tumor Immune Effects in Mouse Pancreas Tumors. J. Clin. Oncol. Res. 2017, 5, 1058.

10. Meng, X.; Feng, R.; Yang, L.; Xing, L.; Yu, J. The Role of Radiation Oncology in Immuno-Oncology. Oncologist 2019, 24, S42-S52. [CrossRef]

11. Ivanov, I.I.; Honda, K. Intestinal commensal microbes as immune modulators. Cell. Host Microbe. 2012, 12, 496-508. [CrossRef] [PubMed]

12. Lynch, S.V.; Pedersen, O. The Human Intestinal Microbiome in Health and Disease. N. Engl. J. Med. 2016, 375, 2369-2379. [CrossRef]

13. Roy, S.; Trinchieri, G. Microbiota: A key orchestrator of cancer therapy. Nat. Rev. Cancer 2017, 5, $271-285$. [CrossRef] [PubMed]

14. Routy, B.; Le Chatelier, E.; Derosa, L.; Duong, C.P.M.; Alou, M.T.; Daillère, R.; Fluckiger, A.; Messaoudene, M.; Rauber, C.; Roberti, M.P.; et al. Gut microbiome influences efficacy of PD-1-based immunotherapy against epithelial tumors. Science 2018, 359, 91-97. [CrossRef] [PubMed]

15. Vétizou, M.; Pitt, J.M.; Daillère, R.; Lepage, P.; Waldschmitt, N.; Flament, C.; Rusakiewicz, S.; Routy, B.; Roberti, M.P.; Duong, C.P.; et al. Anticancer immunotherapy by CTLA-4 blockade relies on the gut microbiota. Science 2015, 350, 1079-1084. [CrossRef] [PubMed]

16. Pitt, J.M.; Vétizou, M.; Gomperts, B.I.; Lepage, P.; Chamaillard, M.; Zitvogel, L. Enhancing the clinical coverage and anticancer efficacy of immune checkpoint blockade through manipulation of the gut microbiota. Oncoimmunology 2016, 6, e1132137. [CrossRef] [PubMed]

17. Dubin, K.; Callahan, M.K.; Ren, B.; Khanin, R.; Viale, A.; Ling, L.; No, D.; Gobourne, A.; Littmann, E.; Huttenhower, $C_{\text {; }}$ et al. Intestinal microbiome analyses identify melanoma patients at risk for checkpoint-blockade-induced colitis. Nat Commun. 2016, 7, e10391. [CrossRef] [PubMed]

18. Sivan, A.; Corrales, L.; Hubert, N.; Williams, J.B.; Aquino-Michaels, K.; Earley, Z.M.; Benyamin, F.W.; Lei, Y.M.; Jabri, B.; Alegre, M.L.; et al. Commensal Bifidobacterium promotes antitumor immunity and facilitates anti-PD-L1 efficacy. Science 2015, 350, 1084-1089. [CrossRef]

19. Chaput, N.; Lepage, P.; Coutzac, C.; Soularue, E.; Le Roux, K.; Monot, C.; Boselli, L.; Routier, E.; Cassard, L.; Collins, M.; et al. Baseline gut micro biota predicts clinical response and colitis in metastatic melanoma patients treated with ipilimumab. Ann. Oncol. 2017, 28, 1368-1379. [CrossRef] [PubMed]

20. Frankel, A.E.; Coughlin, L.A.; Kim, J.; Froehlich, T.W.; Xie, Y.; Frenkel, E.P.; Koh, A.Y. Metagenomic Shotgun Sequencing and Unbiased Metabolomic Profiling Identify Specific Human Gut Microbiota and Metabolites Associated with Immune Checkpoint Therapy Efficacy in Melanoma Patients. Neoplasia 2017, 19, 848-855. [CrossRef] [PubMed]

21. Gopalakrishnan, V.; Spencer, C.N.; Nezi, L.; Reuben, A.; Andrews, M.C.; Karpinets, T.V.; Prieto, P.A.; Vicente, D.; Hoffman, K.; Wei, S.C.; et al. Gut microbiome modulates response to anti-PD-1 immunotherapy in melanoma patients. Science 2018, 359, 97-103. [CrossRef] [PubMed]

22. Matson, V.; Fessler, J.; Bao, R.; Chongsuwat, T.; Zha, Y.; Alegre, M.L.; Luke, J.J.; Gajewski, T.F. The commensal microbiome is associated with anti-PD-1 efficacy in metastatic melanoma patients. Science 2018, 359, 104-108. [CrossRef]

23. Emens, L.A.; Middleton, G. The interplay of immunotherapy and chemotherapy: Harnessing potential synergies. Cancer Immunol. Res. 2015, 5, 436-443. [CrossRef] [PubMed]

24. Pfirschke, C.; Engblom, C.; Rickelt, S.; Cortez-Retamozo, V.; Garris, C.; Pucci, F.; Yamazaki, T.; Poirier-Colame, V.; Newton, A.; Redouane, Y.; et al. Immunogenic Chemotherapy Sensitizes Tumors to Checkpoint Blockade Therapy. Immunity 2016, 44, 343-354. [CrossRef] [PubMed]

25. Song, W.; Shen, L.; Wang, Y.; Liu, Q.; Goodwin, T.J.; Li, J.; Dorosheva, O.; Liu, T.; Liu, R.; Huang, L. Synergistic and low adverse effect cancer immunotherapy by immunogenic chemotherapy and locally expressed PD-L1 trap. Nat. Commun. 2018, 9, 2237. [CrossRef]

26. Mkrtichyan, M.; Najjar, Y.G.; Raulfs, E.C.; Abdalla, M.Y.; Samara, R.; Rotem-Yehudar, R.; Cook, L.; Khleif, S.N. Anti-PD-1 synergizes with cyclophosphamide to induce potent anti-tumor vaccine effects through novel mechanisms. Eur. J. Immunol. 2011, 41, 2977-2986. [CrossRef] 
27. Merlano, M.C.; Merlotti, A.M.; Licitra, L.; Denaro, N.; Fea, E.; Galizia, D.; Di Maio, M.; Fruttero, C.; Curcio, P.; Vecchio, S.; et al. Activation of immune responses in patients with relapsed-metastatic head and neck cancer (CONFRONT phase I-II trial): Multimodality immunotherapy with avelumab, short-course radiotherapy, and cyclophosphamide. Clin. Transl. Radiat. Oncol. 2018, 12, 47-52. [CrossRef]

28. Cui, S. Immunogenic Chemotherapy Sensitizes Renal Cancer to Immune Checkpoint Blockade Therapy in Preclinical Models. Med. Sci. Monit. 2017, 23, 3360-3366. [CrossRef]

29. VanDer Kraak, L.; Goel, G.; Ramanan, K.; Kaltenmeier, C.; Zhang, L.; Normolle, D.P.; Freeman, G.J.; Tang, D.; Nason, K.S.; Davison, J.M.; et al. 5-Fluorouracil upregulates cell surface B7-H1 (PD-L1) expression in gastrointestinal cancers. J. Immunother. Cancer 2016, 4, 65. [CrossRef]

30. Guo, Z.; Wang, H.; Meng, F.; Li, J.; Zhang, S. Combined Trabectedin and anti-PD1 antibody produces a synergistic antitumor effect in a murine modelofovarian cancer. J. Transl. Med. 2015, 13, 247. [CrossRef]

31. Peng, J.; Hamanishi, J.; Matsumura, N.; Abiko, K.; Murat, K.; Baba, T.; Yamaguchi, K.; Horikawa, N.; Hosoe, Y.; Murphy, S.K.; et al. Chemotherapy Induces Programmed Cell Death-Ligand 1 Overexpression via the Nuclear Factor- $\kappa B$ to Foster an Immunosuppressive Tumor Microenvironment in OvarianCancer. Cancer Res. 2015, 75, 5034-5045. [CrossRef]

32. Mesnage, S.J.L.; Auguste, A.; Genestie, C.; Dunant, A.; Pain, E.; Drusch, F.; Gouy, S.; Morice, P.; Bentivegna, E.; Lhomme, C.; et al. Neoadjuvant chemotherapy (NACT) increases immune infiltration and programmed death-ligand 1 (PD-L1) expression in epithelialovariancancer (EOC). Ann. Oncol. 2017, 28, 651-657. [CrossRef]

33. Kok, M.; Voorwerk, L.; Horlings, H.; Sikorska, K.; van der Vijver, K.; Slagter, M.; Warren, S.; Ong, S.; Wiersma, T.; Russell, N.; et al. Adaptive phase II randomized trial of nivolumab after induction treatment in triple negative breast cancer (TONIC trial): Final response data stage I and first translational data. J. Clin. Oncol. 2018, 36, 1012. [CrossRef]

34. Loibl, S.; Untch, M.; Burchardi, N.; Huober, J.B.; Blohmer, J.U.; Grischke, E.M.; Furlanetto, J.; Tesch, H.; Hanusch, C.; Rezai, M.; et al. Randomized phase II neoadjuvant study (GeparNuevo) to investigate the addition of durvalumab to a taxane-anthracycline containing chemotherapy in triple negative breast cancer (TNBC). J. Clin. Oncol. 2018, 36, 104. [CrossRef]

35. NCT03585465: Nivolumab in Combination with Metronomic Chemotherapy in Paediatrics Refractory/Relapsing Solid Tumors or Lymphoma. Available online: https:/clinicaltrials.gov/ct2/show/ NCT03585465 (accessed on 30 October 2018).

36. NCT03683407: Effect of Chemotherapy on TMB in NSCLC. Available online: https://clinicaltrials.gov/ct2/ show/NCT03683407 (accessed on 30 October 2018).

37. Lanitis, E.; Irving, M.; Coukos, G. Targeting the tumor vasculature to enhance T cell activity. Curr. Opin. Immunol. 2015, 33, 55-63. [CrossRef] [PubMed]

38. Stockmann, C.; Schadendorf, D.; Klose, R.; Helfrich, I. The impact of the immune system on tumor: Angiogenesis and vascular remodeling. Front. Oncol. 2014, 4, e69. [CrossRef] [PubMed]

39. Nuti, M.; Zizzari, I.G.; Botticelli, A.; Rughetti, A.; Marchetti, P. The ambitious role of anti angiogenesis molecules: Turning a cold tumor into a hot one. Cancer Treat. Rev. 2018, 70, 41-46. [CrossRef] [PubMed]

40. Hodi, F.S.; Lawrence, D.; Lezcano, C.; Wu, X.; Zhou, J.; Sasada, T.; Zeng, W.; Giobbie-Hurder, A.; Atkins, M.B.; Ibrahim, N.; et al. Bevacizumab plus ipilimumab in patients with metastatic melanoma. Cancer Immunol. Res. 2014, 2, 632-642. [CrossRef] [PubMed]

41. Ozaki, Y.; Matsumoto, K.; Takahashi, M.; Mukohara, T.; Futamura, M.; Masuda, N.; Tsurutani, J.; Yoshimura, K.; Minami, H.; Takano, T. Phase II study of a combination therapy of nivolumab, bevacizumab and paclitaxel in patients with HER2-negative metastatic breast cancer as a first-line treatment (WJOG9917B, NEWBEAT trial). J. Clin. Oncol. 2018, 36, TPS1110. [CrossRef]

42. Liu, J.F.; Herold, C.; Luo, W.; Penson, R.; Horowitz, N.; Konstantinopoulos, P.; Castro, C.; Curtis, J.; Matulonis, U.A.; Cannistra, S.; et al. A phase 2 trial of combination nivolumab and bevacizumab in recurrent ovarian cancer. Ann. Oncol. 2018, 29, viii332-viii358. [CrossRef]

43. Rizvi, N.A.; Antonia, S.J.; Shepherd, F.A.; Chow, L.Q.; Goldman, J.; Shen, Y.; Chen, A.C.; Gettinger, S. Nivolumab (Anti-PD-1; BMS-936558, ONO-4538) Maintenance as Monotherapy or in Combination With Bevacizumab (BEV) for Non-Small Cell Lung Cancer (NSCLC) Previously Treated With Chemotherapy. Int. J. Radiat. Oncol. Biol. Phys. 2014, 90, S32. [CrossRef] 
44. Motzer, R.J.; Powles, T.; Atkins, M.B.; Escudier, B.; McDermott, D.F.; Suarez, C.; Bracarda, S.; Stadler, W.M.; Donskov, F.; Lee, J.L.; et al. IMmotion151: A Randomized Phase III Study of Atezolizumab Plus Bevacizumab vs. Sunitinib in Untreated Metastatic Renal Cell Carcinoma (mRCC). J. Clin. Oncol. 2018, 36, 578. [CrossRef]

45. NCT024243324: A Study of Ramucirumab Plus Pembrolizumab in Participants with Gastric or GEJ Adenocarcinoma, NSCLC, Transitional Cell Carcinoma of the Urothelium, or Biliary Tract Cancer. Available online: https://clinicaltrials.gov/ct2/show/NCT02443324 (accessed on 30 October 2018).

46. Chau, I.; Penel, N.; Arkenau, H.T.; Santana-Davila, R.; Calvo, E.; Soriano, A.O.; Mi, G.; Jin, J.; Ferry, D.; Herbst, R.S.; et al. Safety and antitumor activity of ramucirumab plus pembrolizumab in treatment naïve advanced gastric or gastroesophageal junction (G/GEJ) adenocarcinoma: Preliminary results from a multi-disease phase I study (JVDF). J. Clin. Oncol. 2018, 36, 101. [CrossRef]

47. Amin, A.; Plimack, E.R.; Ernstoff, M.S.; Lewis, L.D.; Bauer, T.M.; McDermott, D.F.; Carducci, M.; Kollmannsberger, C.; Rini, B.I.; Heng, D.Y.C.; et al. Safety and efficacy of nivolumab in combination with sunitinib or pazopanib in advanced or metastatic renal cell carcinoma: The CheckMate 016 study. J. Immunother. Cancer 2018, 6, 109. [CrossRef] [PubMed]

48. Yu, X.; Harden, K.; Gonzalez, L.C.; Francesco, M.; Chiang, E.; Irving, B.; Tom, I.; Ivelja, S.; Refino, C.J.; Clark, H.; et al. The surface protein TIGIT suppresses $\mathrm{T}$ cell activation by promoting the generation of mature immunoregulatory dendritic cells. Nat. Immunol. 2009, 10, 48-57. [CrossRef]

49. Mahoney, K.M.; Rennert, P.D.; Freeman, G.J. Combination cancer immunotherapyand new immunomodulatory targets. Nat. Rev. Drug Discov. 2015, 14, 561-584. [CrossRef] [PubMed]

50. Hung, A.L.; Maxwell, R.; Theodros, D.; Belcaid, Z.; Mathios, D.; Luksik, A.S.; Kim, E.; Wu, A.; Xia, Y.; Garzon-Muvdi, T.; et al. TIGITand PD-1 dual checkpoint blockade enhances antitumor immunity and survival in GBM. Oncoimmunology 2018, 7, e1466769. [CrossRef] [PubMed]

51. NCT03563716: A Study of MTIG7192A in Combination withAtezolizumab in Chemotherapy-Naïve Patients with Locally Advanced or Metastatic Non-Small Cell Lung Cancer. Available online: https://clinicaltrials. gov/ct2/show/NCT03563716 (accessed on 30 October 2018).

52. Melero, I.; Berman, D.M.; Aznar, M.A.; Korman, A.J.; Perez Gracia, J.L.; Haanen, J. Evolving synergistic combinations of targeted immunotherapies to combat cancer. Nat. Rev. Cancer 2015, 15, 457-472. [CrossRef]

53. Woo, S.R.; Turnis, M.E.; Goldberg, M.V.; Bankoti, J.; Selby, M.; Nirschl, C.J.; Bettini, M.L.; Gravano, D.M.; Vogel, P.; Liu, C.L.; et al. Immune inhibitory molecules LAG-3 and PD-1 synergistically regulate T-cell function to promote tumoral immune escape. Cancer Res. 2012, 72, 917-927. [CrossRef]

54. Ascierto, P.A.; Bono, P.; Bhatia, S.; Melero, I.; Nyakas, M.S.; Svane, I.; Callahan, M.K.; Gajewski, T.; Gomez-Roca, C.A.; Hodi, F.S.; et al. Initial efficacy of anti-lymphocyte activation gene-3 (anti-LAG-3; BMS-986016) in combination with nivolumab (nivo) in pts with melanoma (MEL) previously treated with anti-PD-1/PD-L1 therapy. J. Clin. Oncol. 2017, 35, 9520. [CrossRef]

55. Hong, D.S.; Schoffski, P.; Calvo, A.; Sarantopoulos, J.; De Olza, M.O.; Carvajal, R.D.; Prawira, A.; Kyi, C.; Esaki, T.; Akerley, W.L.; et al. Phase I/II study of LAG525 \pm spartalizumab (PDR001) in patients (pts) with advanced malignancies. J. Clin. Oncol. 2018, 36, 3012. [CrossRef]

56. Anderson, A.C.; Joller, N.; Kuchroo, V.K. Lag-3, Tim-3, and TIGIT: Co-inhibitory receptors with specialized functions in immune regulation. Immunity 2016, 44, 989-1004. [CrossRef] [PubMed]

57. NCT02817633: A Phase 1 Study of TSR-022, an Anti-TIM-3 Monoclonal Antibody, in Patients with Advanced Solid Tumors (AMBER). Available online: https://clinicaltrials.gov/ct2/show/NCT02817633 (accessed on 30 October 2018).

58. Ribas, A.; Dummer, R.; Puzanov, I.; VanderWalde, A.; Andtbacka, R.H.I.; Michielin, O.; Olszanski, A.J.; Malvehy, J.; Cebon, J.; Fernandez, E.; et al. Oncolytic Virotherapy Promotes Intratumoral T Cell Infiltration and Improves Anti-PD-1 Immunotherapy. Cell 2017, 170, 1109. [CrossRef] [PubMed]

59. La Rocca, C.J.; Warner, S.G. Oncolytic viruses and checkpoint inhibitors: Combination therapy in clinical trials. Clin. Transl. Med. 2018, 7, 35. [CrossRef]

60. Chesney, J.; Puzanov, I.; Collichio, F.; Singh, P.; Milhem, M.M.; Glaspy, J.; Hamid, O.; Ross, M.; Friedlander, P.; Garbe, C.; et al. Randomized, Open-Label Phase II Study Evaluating the Efficacy and Safety of TalimogeneLaherparepvec in Combination With Ipilimumab Versus Ipilimumab Alone in Patients With Advanced, Unresectable Melanoma. J. Clin. Oncol. 2018, 36, 1658-1667. [CrossRef] 
61. NCT02263508: Pembrolizumab with or without TalimogeneLaherparepvec or TalimogeneLaherparepvec Placebo in Unresected Melanoma (KEYNOTE-034). Available online: https://clinicaltrials.gov/ct2/show/ NCT02263508 (accessed on 30 October 2018).

62. Andtbacka, R.H.I.; Ross, M.I.; Agarwala, S.S.; Taylor, M.H.; Vetto, J.T.; Neves, R.I.; Daud, A.; Khong, H.T.; Ungerleider, R.S.; Tanaka, M.; et al. Final results of a phase II multicenter trial of HF10, a replication-competent HSV-1 oncolytic virus, and ipilimumab combination treatment in patients with stage IIIB-IV unresectable or metastatic melanoma. J. Clin. Oncol. 2017, 35, 9510. [CrossRef]

63. NCT02798406: Combination Adenovirus + Pembrolizumab to Trigger Immune Virus Effects (CAPTIVE). Available online: https:/clinicaltrials.gov/ct2/show/NCT02798406 (accessed on 30 October 2018).

64. Haddad, D. Genetically Engineered Vaccinia Viruses As Agents for Cancer Treatment, Imaging, and Transgene Delivery. Front. Oncol. 2017, 7, 96. [CrossRef] [PubMed]

65. Anthoney, A.; Samson, A.; West, E.; Turnbull, S.J.; Scott, K.; Tidswell, E.; Kingston, J.; Johnpulle, M.; Noutch, S.; Bendjama, K.; et al. Single intravenous preoperative administration of the oncolytic virus Pexa-Vec to prime anti-tumor immunity. J. Clin. Oncol. 2018, 36, 3092. [CrossRef]

66. NCT03206073: A Phase I/II Study of Pexa-Vec Oncolytic Virus in Combination with Immune Checkpoint Inhibition in Refractory Colorectal Cancer. Available online: https://clinicaltrials.gov/ct2/show/NCT03206073 (accessed on 30 October 2018).

67. NCT02977156: Immunization Strategy with Intra-tumoral Injections of Pexa-Vec With Ipilimumab in Metastatic/Advanced Solid Tumors. (ISI-JX). Available online: https://clinicaltrials.gov/ct2/show/ NCT02977156 (accessed on 30 October 2018).

68. NCT02307149: Intratumoral CAVATAK (CVA21) and Ipilimumab in Patients with Advanced Melanoma (VLA-013 MITCI) (MITCI). Available online: https:/clinicaltrials.gov/ct2/show/NCT02307149 (accessed on 30 October 2018).

69. Silk, A.W.; Kaufman, H.; Gabrail, N.; Mehnert, J.; Bryan, J.; Norrell, J.; Medina, D.; Bommareddy, P.; Shafren, D.; Grose, M.; et al. Phase 1b study of intratumoralCoxsackievirus A21 (CVA 21) and systemic pembrolizumab in a dvanced melanoma patients: Interim results of the CAPRA clinical trial. Cancer Res. 2017, 77, CT026. [CrossRef]

70. Mahalingam, D.; Fountzilas, C.; Moseley, J.L.; Noronha, N.; Cheetham, K.; Dzugalo, A.; Nuovo, G.; Gutierrez, A.; Arora, S.P.; et al. A study of REOLYSIN in combination with pembrolizumab and chemotherapy in patients (pts) with relapsed metastatic adenocarcinoma of the pancreas (MAP). J. Clin. Oncol. 2017, 35, e15753. [CrossRef]

71. NCT02620423: Study of Pembrolizumab with REOLYSIN ${ }^{\circledR}$ and Chemotherapy in Patients with Advanced Pancreatic Adenocarcinoma. Available online: https://clinicaltrials.gov/ct2/show/NCT02620423 (accessed on 30 October 2018).

72. Frederick, D.T.; Piris, A.; Cogdill, A.P.; Cooper, Z.A.; Lezcano, C.; Ferrone, C.R.; Mitra, D.; Boni, A.; Newton, L.P.; Liu, C.; et al. BRAF inhibition is associated with enhanced melanoma antigen expression and a more favorable tumor microenvironment in patients with metastatic melanoma. Clin. Cancer Res. 2013, 19, 1225-1231. [CrossRef]

73. Comin-Anduix, B.; Chodon, T.; Sazegar, H.; Matsunaga, D.; Mock, S.; Jalil, J.; Escuin-Ordinas, H.; Chmielowski, B.; Koya, R.C.; Ribas, A.; et al. The oncogenic BRAF kinase inhibitor PLX4032/RG7204 does not affect the viability or function of human lymphocytes across a wide range of concentrations. Clin. Cancer Res. 2010, 16, 6040-6048. [CrossRef] [PubMed]

74. Wilmott, J.S.; Long, G.V.; Howle, J.R.; Haydu, L.E.; Sharma, R.N.; Thompson, J.F.; Kefford, R.F.; Hersey, P.; Scolyer, R.A. Selective BRAF inhibitors induce marked T-cell infiltration into human metastatic melanoma. Clin. Cancer Res. 2012, 18, 1386-1394. [CrossRef] [PubMed]

75. Bradley, S.D.; Chen, Z.; Melendez, B.; Talukder, A.; Khalili, J.S.; Rodriguez-Cruz, T.; Liu, S.; Whittington, M.; Deng, W.; Li, F.; et al. BRAFV600E co-opts a conserved MHC class I internalization pathway to diminish antigen presentation and CD8+ T-cell recognition of melanoma. Cancer Immunol. Res. 2015, 3, 602-609. [CrossRef]

76. Koya, R.C.; Mok, S.; Otte, N.; Blacketor, K.J.; Comin-Anduix, B.; Tumeh, P.C.; Minasyan, A.; Graham, N.A.; Graeber, T.G.; Chodon, T.; et al. BRAF inhibitor vemurafenib improves the antitumor activity of adoptive cell immunotherapy. Cancer Res. 2012, 72, 3928-3937. [CrossRef] 
77. Knight, D.A.; Ngiow, S.F.; Li, M.; Parmenter, T.; Mok, S.; Cass, A.; Haynes, N.M.; Kinross, K.; Yagita, H.; Koya, R.C.; et al. Host immunity contributes to the anti-melanoma activity of BRAF inhibitors. J. Clin. Investig. 2016, 126, 402-403. [CrossRef]

78. Hooijkaas, A.; Gadiot, J.; Morrow, M.; Stewart, R.; Schumacher, T.; Blank, C.U. Selective BRAF inhibition decreases tumor-resident lymphocyte frequencies in a mouse model of human melanoma. Oncoimmunology 2012, 1, 609-617. [CrossRef]

79. Cooper, Z.A.; Juneja, V.R.; Sage, P.T.; Frederick, D.T.; Piris, A.; Mitra, D.; Lo, J.A.; Hodi, F.S.; Freeman, G.J.; Bosenberg, M.W.; et al. Response to BRAF inhibition in melanoma is enhanced when combined with immune checkpoint blockade. Cancer Immunol. Res. 2014, 2, 643-654. [CrossRef]

80. Hu-Lieskovan, S.; Mok, S.; Moreno, B.H.; Tsoi, J.; Faja, L.R.; Goedert, L.; Pinheiro, E.M.; Koya, R.C.; Graeber, T.G.; Comin-Anduix, B.; et al. Improved antitumor activity of immunotherapy with BRAF and MEK inhibitors in BRAFV600E melanoma. Sci. Transl. Med. 2015, 7, 279ra41. [CrossRef]

81. Ribas, A.; Hodi, F.S.; Callahan, M.; Konto, C.; Wolchok, J. Hepatotoxicity with combination of vemurafenib and ipilimumab. N. Engl. J. Med. 2013, 368, 1365-1366. [CrossRef]

82. Minor, D.R.; Puzanov, I.; Callahan, M.K.; Hug, B.A.; Hoos, A. Severe gastrointestinal toxicity with administration of trametinib in combination with dabrafenib and ipilimumab. Pigment Cell Melanoma Res. 2015, 28, 611-612. [CrossRef] [PubMed]

83. Puzanov, I.; Callahan, M.; Gerald, P.; Linette, G.; Luke, J.J.; Sosmanet, J.A.; Wolchok, J.D.; Hamid, O.; Minor, D.R.; Orford, K.W.; et al. Phase 1 study of the BRAF inhibitor dabrafenib (D) with or without the MEK inhibitor trametinib (T) in combination with ipilimumab (Ipi) for V600E/K mutation-positive unresectable or metastatic melanoma (MM). J. Clin. Oncol. 2014, 32, 2511. [CrossRef]

84. NCT01656642: A Phase 1b Study of Atezolizumab in Combination with BRAFV600-Mutation Positive Metastatic Melanoma. Available online: https:/clinicaltrials.gov/ct2/show/NCT01656642 (accessed on 30 October 2018).

85. Ribas, A.; Hodi, F.; Lawrence, D.; Atkinson, V.; Starodub, A.; Carlino, M.S.; Fisher, R.A.; Long, G.V.; Miller, W.H.; Huang, Y.; et al. Pembrolizumab (pembro) in combination with dabrafenib (D) and trametinib (T) for BRAF-mutant advanced melanoma: Phase 1 KEYNOTE-022 study. J. Clin. Oncol. 2016, 34, 3014. [CrossRef]

86. Sullivan, R.J.; Gonzalez, R.; Lewis, K.D.; Hamid, O.; Infante, J.R.; Patel, M.R.; Hodi, F.S.; Wallin, J.; Pitcher, B.; Cha, E.; et al. Atezolizumab (A) + cobimetinib (C) + vemurafenib (V) in BRAFV600-mutant metastatic melanoma (mel): Updated safety and clinical activity. J. Clin. Oncol. 2017, 35, 3063. [CrossRef]

87. Larmonier, N.; Janikashvili, N.; La Casse, C.J.; Larmonier, C.B.; Cantrell, J.; Situ, E.; Lundeen, T.; Bonnotte, B.; Katsanis, E. Imatinib mesylate inhibits CD4+ CD25+ regulatory $\mathrm{T}$ cell activity and enhances active immunotherapy against BCR-ABL-tumors. J. Immunol. 2008, 181, 6955-6963. [CrossRef] [PubMed]

88. Ménard, C.; Blay, J.Y.; Borg, C.; Michiels, S.; Ghiringhelli, F.; Robert, C.; Nonn, C.; Chaput, N.; Taïeb, J.; Delahaye, N.F.; et al. Natural killer cell IFN-gamma levels predict long-term survival with imatinib mesylate therapy in gastrointestinal stromal tumor-bearing patients. Cancer Res. 2009, 69, 3563-3569. [CrossRef] [PubMed]

89. Balachandran, V.P.; Cavnar, M.J.; Zeng, S.; Bamboat, Z.M.; Ocuin, L.M.; Obaid, H.; Sorenson, E.C.; Popow, R.; Ariyan, C.; Rossi, F.; et al. Imatinib potentiates antitumor T cell responses in gastrointestinal stromal tumor through the inhibition of Ido. Nat. Med. 2011, 17, 1094-1100. [CrossRef] [PubMed]

90. Seifert, A.M.; Zeng, S.; Zhang, J.Q.; Kim, T.S.; Cohen, N.A.; Beckman, M.J.; Medina, B.D.; Maltbaek, J.H.; Loo, J.K.; Crawley, M.H.; et al. PD-1/PD-L1 Blockade Enhances T-cell Activity and Antitumor Efficacy of Imatinib in Gastrointestinal Stromal Tumors. Clin. Cancer Res. 2017, 23, 454-465. [CrossRef]

91. NCT01738139: Ipilimumab and Imatinib Mesylate in Treating Participants with Metastatic or Unresectable Solid Tumors. Available online: https://clinicaltrials.gov/ct2/show/NCT01738139 (accessed on 30 October 2018).

92. Reilley, M.J.; Bailey, A.; Subbiah, V.; Janku, F.; Naing, A.; Falchook, G.; Karp, D.; Piha-Paul, S.; Tsimberidou, A.; $\mathrm{Fu}$, S.; et al. Phase I clinical trial of combination imatinib and ipilimumab in patients with advanced malignancies. J. Immunother. Cancer 2017, 5, 35. [CrossRef]

93. Cash, H.; Shay, S.; Moree, E.; Cariso, A.; Uppaluri, R.; Van Waes, C.; Allen, C. mTOR and MEK1/2 inhibition differentially modulate tumor growth and the immune microenvironment in syngeneic models of oral cavity cancer. Onco. Target 2015, 6, 36400-36417. [CrossRef] 
94. Moore, E.C.; Cash, H.A.; Caruso, A.M.; Uppaluri, R.; Hodge, J.W.; Van Waes, C.; Allen, C.T. Enhanced tumor control with combination mTOR and PD-L1 inhibition in syngeneic oral cavity cancers. Cancer Immunol. Res. 2016, 4, 611-620. [CrossRef]

95. Goel, S.; De Cristo, M.J.; Watt, A.C.; Brin Jones, H.; Sceneay, J.; Li, B.B.; Khan, N.; Ubellacker, J.M.; Xie, S.; Metzger-Filho, O.; et al. CDK4/6 inhibition triggers anti-tumour immunity. Nature 2017, 548, 471-475. [CrossRef]

96. Zhang, J.; Bu, X.; Wang, H.; Zhu, Y.; Geng, Y.; Nihira, N.T.; Tan, Y.; Ci, Y.; Wu, F.; Dai, X.; et al. Cyclin D-CDK4 kinase destabilizes PD-L1 via cullin 3-SPOP to control cancer immune surveillance. Nature 2018, 553, 91-95. [CrossRef]

97. Teo, Z.L.; Versaci, S.; Dushyanthen, S.; Caramia, F.; Savas, P.; Mintoff, C.P.; Zethoven, M.; Virassamy, B.; Luen, S.J.; McArthur, G.A.; et al. Combined CDK4/6 and PI3K $\alpha$ Inhibition Is Synergistic and Immunogenic in Triple-Negative Breast Cancer. Cancer Res. 2017, 77, 6340-6352. [CrossRef]

98. NCT02130466: A Study of the Safety and Efficacy of Pembrolizumab (MK-3475) in Combination with Trametinib and Dabrafenib in Participants with Advanced Melanoma (MK-3475-022/KEYNOTE-022). Available online: https://clinicaltrials.gov/ct2/show/NCT02130466 (accessed on 30 October 2018).

99. Nanda, V.G.Y.; Peng, W.; Hwu, P.; Davies, M.A.; Ciliberto, G.; Fattore, L.; Malpicci, D.; Aurisicchio, L.; Ascierto, P.A.; Croce, C.M.; et al. Melanoma and immunotherapy bridge 2015. Naples, Italy. 1-5 December 2015. J. Transl. Med. 2016, 14 (Suppl. 1), 65. [CrossRef] [PubMed]

100. Borg, C.; Terme, M.; Taïeb, J.; Ménard, C.; Flament, C.; Robert, C.; Maruyama, K.; Wakasugi, H.; Angevin, E.; Thielemans, K.; et al. Novel mode of action of c-kit tyrosine kinase inhibitors leading to NK cell-dependent antitumor effects. J. Clin.Investig. 2004, 114, 379-388. [CrossRef] [PubMed]

101. Van Dongen, M.; Savage, N.D.; Jordanova, E.S.; Briaire-de Bruijn, I.H.; Walburg, K.V.; Ottenhoff, T.H.; Hogendoorn, P.C.; van der Burg, S.H.; Gelderblom, H.; van Hall, T. Anti-inflammatory M2 type macrophages characterize metastasized and tyrosine kinase inhibitor-treated gastrointestinal stromal tumors. Int. J. Cancer 2010, 127, 899-909. [CrossRef]

102. Loukinova, E.; Dong, G.; Enamorado-Ayalya, I.; Thomas, G.R.; Chen, Z.; Schreiber, H.; VanWaes, C. Growth regulated oncogene-alpha expression by murine squamous cell carcinoma promotes tumor growth, metastasis, leukocyte infiltration and angiogenesis by a host CXC receptor- 2 dependent mechanism. Oncogene 2000, 19, 3477-3486. [CrossRef] [PubMed]

103. Moslehi, J.J.; Salem, J.E.; Sosman, J.A.; Lebrun-Vignes, B.; Johnson, D.B. Increased reporting of fatal immune checkpoint inhibitor-associated myocarditis. Lancet 2018, 391, 933. [CrossRef]

104. Tajiri, K.; Ieda, M. Cardiac Complications in Immune Checkpoint Inhibition Therapy. Front. Cardiovasc. Med. 2019, 6, 3. [CrossRef] [PubMed] 